\title{
RESILIENCE ASSESSMENTS IN SOCIAL WORK: THE CASE OF THE SA DEPARTMENT OF DEFENCE
}

\section{Adrian D. van Breda}

\section{INTRODUCTION}

In recent years there has been a growing interest in social work literature in the strengths (Saleebey, 2008) and assets (Kretzmann \& McKnight, 1993) of people and systems. This interest has involved a shift away from the dominant preoccupation with pathology and deficits that has characterised much of the history of social work (Bendor, Davidson \& Skolnik, 1997; Weick \& Saleebey, 1995). Part of the appeal of the strengths perspective is its alignment with the social values of human dignity and respect for client self-determination (Healy, 2005). While the strengths and resilience perspectives have become well established in social work, there is relatively little literature on the processes of assessment from these perspectives. In many ways the resilience and strengths perspectives are just that - perspectives, ways of looking at the world, a political stance that we as practitioners take towards our client systems. This is appropriate as it points towards the value base of social work; but these perspectives must also be translated into clear practice guidelines.

The purpose of this paper is illustrate how these perspectives can be translated effectively into practice through the development of a cluster of assessment tools. The paper will advance examples of how the resilience perspective has been applied to social work practice in the South African Department of Defence (DOD). There is a specific focus on the assessment of family resilience or strengths, as the family is a central client system for military social workers. The paper thus begins with a brief overview of the resilience perspective, followed by three tools that have been developed by the DOD - a conceptual model of family resilience, an ecometric scale that measures family resilience and a clinical protocol for the assessment of family resilience. These tools form a triangulated package - integrating theory, a scale and an interview schedule - which serves to apply the resilience perspective in practice. A brief case example is included to illustrate the use of these tools. It is hoped that the process of developing these tools and the tools themselves may serve to stimulate further development of resiliencebased assessments.

\section{THE RESILIENCE PERSPECTIVE}

Resilience is a multifaceted field of study that has been addressed by social workers, psychologists, sociologists, educators and many others over the past few decades. In short, resilience theory addresses the strengths that people and systems demonstrate that enable them to rise above adversity (Van Breda, 2001).

The emergence of resilience theory is associated with a reduction in emphasis on pathology and an increase in emphasis on strengths (Rak \& Patterson, 1996). O'Leary (1998:426) notes:

Psychologists [and social workers] have recently called for a move away from vulnerability/deficit models to focus instead on triumphs in the face of adversity ... This call for a focus on strengths parallels that of a number of other investigators in child development..., medical sociology... and education... The potential theoretical, empirical and policy significance of the proposed paradigm shift from illness to health, from vulnerability to thriving, from deficit to protection and beyond ought not be 
underestimated. The precedent for this paradigm shift is growing in the scientific literature.

Hawley and De Haan (1996:283) note a similar trend in family therapy:

In recent years there has been a movement in the family field toward strengths-based and away from deficit-based models. For example, in family therapy the solution-focused and narrative models assume that clients possess resources that will allow them to resolve their difficulties... An emphasis on resilience in clients has often accompanied this focus on strengths.

McCubbin and McCubbin (1992:150) have identified five major developments in the field of family social work during the 1970s and 1980s, the third and fifth of which are of primary relevance for this paper:

- There has been ongoing evaluation of the efficacy of interventions targeted at the family system;

- The revival of family stress theory has highlighted important dimensions of family functioning for intervention;

- Various family typologies have been developed to guide family assessment and intervention;

- Theory and research have been advanced to promote family strengths and capabilities, which have enhanced intervention;

- Family assessment and measurement tools have been developed for use in family research, clinical assessment and programme evaluation.

It is important to note the growth in theory of family functioning and particularly of family resilience, and the consequent development of assessment technologies that are in support of these theories. The joining of practice theory with assessment tools is central to the work presented in this paper.

Pearlin and Schooler (1982) note that researchers have historically tended to confine their attention to pathology and problems. The advance of our knowledge of how people survive, cope and even thrive has been left largely to clinicians in the field. This has had four main effects:

- Firstly, it has created the impression that coping in the face of adversity is an idiosyncratic phenomenon rather than widespread or even normative (see also Antonovsky, 1979);

- Secondly, it has tended to locate such coping within unique individuals, thereby overlooking the possibility of "institutionalised solutions to common life tasks" (Pearlin \& Schooler, 1982:110; see also Saleebey, 1997);

- Thirdly, it has elevated pathology into the high realm of "Science", and relegated coping to the homely world of folklore (see also Goldstein, 1997);

- Fourthly, it has led clinicians, including social workers, to resist acknowledging the validity and presence of strengths in their clients. Barnard (1994:136) refers to this as the Law of the Hammer, which "suggests that if you give young children a hammer, everything they come in contact with will need pounding. One of the primary 'hammers' of the human services fields has been psychopathology, and related nomenclature."

There is, of course, the danger of turning the notion of resilience into a kind of rugged, rigid, "just-shake-it-off”, “don't-look-back", “Teflon-coated” resilience, which renders the individual 
or system "brittle" and vulnerable to stress (Schwartz, 1997). What is advocated in the resilience literature, however, is a kind of resilience that is compassionate, flexible and in touch with life, and which promotes the ability to bounce back, without disregarding the pain that is often part of life (Schwartz, 1997).

One of the difficulties experienced with some of the literature on resilience theory is the difficult application of these theories and principles in direct practice, notably in the area of assessments. This difficulty is, perhaps, a result of the perspectival nature of resilience theory and the pressing vulnerabilities and pain of many clients. In order to remedy this difficulty, the Directorate Social Work of the DOD developed a multicultural standardised rating scale and clinical assessment framework integrated with an articulated model of family resilience. This paper will first outline the model, which is now used in all clinical assessments in the DOD. Then the rating scale and assessment framework will be introduced as practice-based operationalisations of the model.

\section{SA DOD RESILIENCE MODEL OF SOCIAL HEALTH}

The need for a model of family resilience in the DOD grew out of a clinical and community need to support families during military deployments. Initial exploratory research was conducted in the mid-1990s to determine how families experienced the stress of deployments and to uncover helpful coping patterns (Van Breda, 1995, 1997b). This resulted in the formulation of the concept of "deployment resilience", which is defined as "the capacity of families to resist the stress of deployments" (Van Breda, 1997a, 1999). Subsequently, a psychoeducational intervention was developed to enhance the deployment resilience of military families (Van Breda, 1997a, 1999).

In 1999 the DOD initiated a process of assessing the health status of all soldiers who are earmarked for international deployments - the Concurrent Health Assessments (CHA). The CHA required social workers to assess several thousand soldiers at six-monthly intervals (though later this was reduced to annual). This in turn necessitated the development of an assessment model and procedure (Directorate Social Work, 2001). In March 2000 the first group of soldiers underwent the social work CHA using the SA DOD Resilience Model of Social Health (Van Breda, 2002a).

The Directorate Social Work made a deliberate decision to approach these assessments from a resilience or strengths perspective, because it believed that this perspective was most congruent with the values and principles of social work. An extensive review of resilience literature was conducted, with particular attention to literature concerning the resilience of military families to deployment stress (Van Breda, 2001). From this review McCubbin and McCubbin's (1996) Resiliency Model of Family Adjustment and Adaptation emerged as a highly developed and empirically grounded model. The McCubbins (one a social worker and the other a nurse by training) are primarily researchers and their model is a highly sophisticated attempt to predict family outcomes of life stressors. As a result their model, while empirically impressive, is too complex for use in daily practice. Their model was therefore simplified somewhat to facilitate its use in clinical practice. The key components of their model formed the major frame of the SA DOD Resilience Model.

In addition a number of new constructs were added that were considered salient to the SA DOD context (Van Breda, 2002b). For instance, the dimension Work-to-Family Interference (Frone, Yardley \& Markel, 1997; Googins, 1991; Netemeyer, Boles \& McMurrian, 1996; Segal, 1989), which is not mentioned in the McCubbins' work, was added, based on clinical experience of 
the ways in which work and family life spill into each other. Another example is the use of the term Generalised Resistance Resources - the term was cannibalised from Antonovsky's (1979, 1988) model of salutogenesis and the content is a composite of many individual and family strengths.

The SA DOD Resilience Model comprises two broad concepts, viz. vulnerability and resilience. Vulnerability refers to "the interpersonal and organizational condition of the family system" (McCubbin \& McCubbin, 1996:17) and is determined by (McCubbin \& McCubbin, 1993:28):

(1) The accumulation, or pileup, of demands on or within the family unit, such as financial debts, poor health status of relatives, and changes in a parent's work role or work environment, and (2) the normative trials and tribulations associated with the family's particular life-cycle stage with all of its demands and changes.

Resilience, in the context of families, refers to "key processes that enable families to cope more effectively and emerge hardier from crises or persistent stresses, whether from within or from outside the family" (Walsh, 1996:263). Other authors have stated that "Family resilience describes the path a family follows as it adapts and prospers in the face of stress, both in the present and over time. Resilient families respond positively to these conditions in unique ways, depending on the context, developmental level, the interactive combination of risk and protective factors, and the family's shared outlook" (Hawley \& De Haan, 1996:293).

\section{FIGURE 1}

\section{SA DOD RESILIENCE MODEL OF SOCIAL HEALTH}

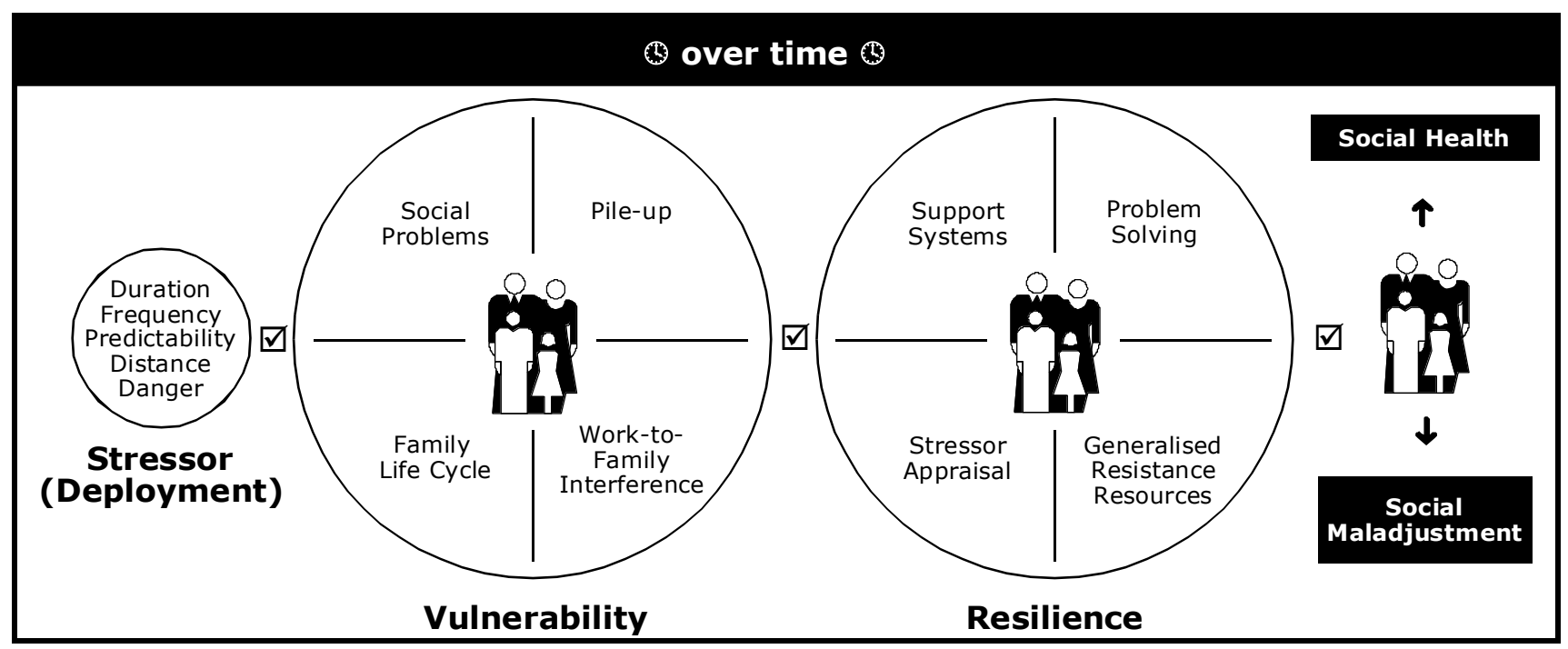

The model is illustrated in Figure 1 (Van Breda, 2008b). Each element of the model is briefly defined below (Van Breda, 2004:228-231).

- Family: the network of significant and meaningful relationships between a group of individuals who experience a sense of emotional affiliation and mutual obligation.

- Social health: the relatively low vulnerability and high resilience of people that enable them to deal effectively with life stress, notably the stress of a military operation (Directorate Social Work, 2001:5).

- Vulnerability: the likelihood of wellness breakdown in a family system in response to life stress, notably the stress of a military operation. 
- Social problems: to the presence of persistent (non-crisis) social pathologies in the family system over the preceding six months, which combine to create vulnerability and social unhealth.

- Pile-up: the accumulation, over a six-month period, of multiple life stressors, crises or events (including transitional events in the family life cycle), which require complex and multiple role changes in the family system, which contributes to increased vulnerability and social unhealth.

- Family life cycle: the presence of difficulties related to the transitions between stages in the life cycle or the challenges of a particular stage of the cycle, which contributes to increased vulnerability and social unhealth.

- Work-to-family interference: the presence of stressors in the workplace that may spill over into the family system, which combine to create vulnerability and social unhealth.

- Resilience: the presence of key processes and properties of family systems that enable them to cope more effectively and emerge stronger from life stress, notably the stress of a military operation.

- Social support: the ability of the family system to access quality and sufficient support systems in times of need, which contributes to increased resilience and social health.

- Problem solving: the ability of the family system to identify problems, generate alternatives, implement solutions and evaluate solutions, which contributes to increased resilience and social health.

- Stressor appraisal: the way in which the stress of a military operation is perceived (seen), appraised (evaluated) and interpreted (given meaning) by family systems, which contributes to increased resilience and social health.

- Generalised resistance resources (GRRs): the presence of a variety of creative and dynamic resources in family members and the family system that enable families to resist life stress, which contributes to increased resilience and social health.

The Resilience Model, with its two main dimensions (Vulnerability and Resilience) and its eight subconstructs, has been in use by the Directorate Social Work since the beginning of 2000. It has been well tested in the field in both assessment and practice, and has held up to such use. The Directorate has demonstrated its confidence in the model by extending its application to organisational interventions and also to the support function of social work supervision. In this way the Directorate has located the model as a central organising framework for all social work practice.

\section{MILITARY SOCIAL HEALTH INDEX}

Using the SA DOD Resilience Model of Social Health as a theoretical foundation, the author developed a standardised rating scale called the Military Social Health Index (MSHI) (Van Breda, 2004). The details of the design and validation are provided elsewhere (Van Breda, 2008a, b).

The MSHI was developed in four of the most common languages used in the SA DOD, viz. English, Afrikaans, Zulu and Setswana. It was designed as a multicultural/multilingual tool from conception, rather than being developed as an English scale and then translated and adjusted for use among other culture groups. The scale, in alignment with the Resilience Model, measures seven constructs, viz. social problems, pile-up, work-to-family interference, social support, problem solving, stressor appraisal and generalised resistance resources. Family 
life cycle, one of the vulnerability subconstructs, was omitted from the MSHI, because the construct is too unique or specific to each life cycle stage to incorporate into a standardised instrument. Only stressor appraisal measures a distinctly military construct. Table 1 provides a sample of the items from each scale.

\section{TABLE 1}

\section{MILITARY SOCIAL HEALTH INDEX: SAMPLE ITEMS}

\begin{tabular}{|c|c|}
\hline Scale & Sample Items \\
\hline Social Problems & $\begin{array}{l}\text { Someone in my family drinks too much alcohol. } \\
\text { My family has financial problems. } \\
\text { Someone in my family physically hurts/hits another family member. }\end{array}$ \\
\hline Pile-up & $\begin{array}{l}\text { Someone in my family was hospitalised. } \\
\text { Someone in my family was arrested. } \\
\text { There was an unplanned pregnancy in my family. }\end{array}$ \\
\hline $\begin{array}{l}\text { Work-to-Family } \\
\text { Interference }\end{array}$ & $\begin{array}{l}\text { My unit does not respect my responsibilities towards my extended } \\
\text { family. } \\
\text { Deployments occur with little warning. } \\
\text { The organisation has unrealistic expectations of me. }\end{array}$ \\
\hline Social Supports & $\begin{array}{l}\text { My family is appreciated by others. } \\
\text { There are a variety of support systems available to my family. } \\
\text { Members of my community will help in an emergency. }\end{array}$ \\
\hline Problem Solving & $\begin{array}{l}\text { We resolve most of the problems in our family. } \\
\text { We look for solutions that everyone agrees on. } \\
\text { When solutions do not work, our family looks for other solutions. }\end{array}$ \\
\hline Stressor Appraisal & $\begin{array}{l}\text { My family understands the purpose of deployments. } \\
\text { Deployments make life interesting. } \\
\text { My family is proud that I am a soldier. }\end{array}$ \\
\hline $\begin{array}{l}\text { Generalised } \\
\text { Resistance } \\
\text { Resources }\end{array}$ & $\begin{array}{l}\text { My family stands together. } \\
\text { We believe things in life will get better. } \\
\text { We respect each other in our family. }\end{array}$ \\
\hline
\end{tabular}

The central psychometric properties of the MSHI are provided in Table 2 (complete validation data can be obtained in Van Breda, 2004; 2008b).

It can be seen that the MSHI, particularly the four resilience constructs, demonstrates good reliability (with all alpha coefficients above .80), acceptable measurement error (all below 8\%) and good construct validity at item level (all above .40).

We therefore have a standardised measurement instrument, based on a theoretically sound model of family resilience, that demonstrates good measurement properties. This scale can be used in clinical settings for the assessment of family resilience. It can also be used with a single-system design (Bloom, Fischer \& Orme, 1995) to measure progress over time. The instrument is relatively brief (a total of 100 items), multilingual and culturally sensitive. 
TABLE 2

SELECTED VALIDATION RESULTS

\begin{tabular}{|l|c|c|c|}
\hline Scale & ALPHA $^{1}$ & SEM $^{2}$ & Construct Validity $^{\mathbf{3}}$ \\
\hline Social Problems & .870 & 6.38 & .532 \\
\hline Pile-up & .801 & 5.71 & .407 \\
\hline Work-to-Family Interference & .888 & 7.39 & .573 \\
\hline Social Supports & .934 & 4.72 & .686 \\
\hline Problem Solving & .963 & 3.60 & .791 \\
\hline Stressor Appraisal & .929 & 5.15 & .669 \\
\hline Generalised Resistance Resources & .956 & 3.60 & .766 \\
\hline
\end{tabular}

\section{SA DOD RESILIENCE MODEL ASSESSMENT PROTOCOL}

While a standardised rating scale that is aligned with the SA DOD Resilience Model was a significant step towards theoretically integrated assessment practice in the DOD, further work was needed. Social workers evidenced difficulties applying the model in their clinical assessments. The need was thus identified to develop a tool for clinical assessments to enable social workers to competently assess clients within the Resilience Model framework.

A team of researchers, with experience in clinical assessments, the MSHI development and the CHA procedures, designed a one-page (A3 size) clinical assessment framework called the Resilience Model Assessment Protocol (RMAP) (Figure 2). The RMAP guides social workers in conducting a comprehensive psychosocial assessment that is aligned with the Resilience Model of Social Health. It highlights key questions under each of the eight constructs of the Resilience Model, in much the same way as the MSHI does. Family life cycle, which was omitted from the MSHI, is incorporated into the RMAP, because the interview format of the assessment allows for specific questions to be asked related to the particular stage of the life cycle of the client. In addition, the RMAP addresses the main dimensions of the Resilience Model - stressor, vulnerability, resilience and social health.

In addition to its content, the RMAP was designed to facilitate three aspects of assessments that we had recognised to be problematic in the way military social workers conducted assessments. Firstly, social workers struggled to ask the kinds of questions that would elicit a comprehensive picture of both the vulnerability and resilience of military families. Typically, social workers were skilled at assessing vulnerability, but not resilience. Secondly, social workers struggled to record the evidence collected during assessment interviews, and when evidence was recorded it tended to be rather hodgepodge and not systematic. And thirdly, social workers were sometimes ineffective in drawing the evidence through to an overall assessment or formulation of the case.

\footnotetext{
1 Mean internal consistency (Cronbach's Alpha) across four validation samples comprising 500 respondents each $(\mathrm{n}=2,000)$.

${ }^{2}$ Standard Error of Measurement, based on the same validation sample $(n=2,000)$.

${ }^{3}$ Construct validity, derived from the mean corrected item-total correlations, using the same validation sample as above $(n=2,000)$.
} 
FIGURE 2

SA DOD RESILIENCE MODEL ASSESSMENT PROTOCOL

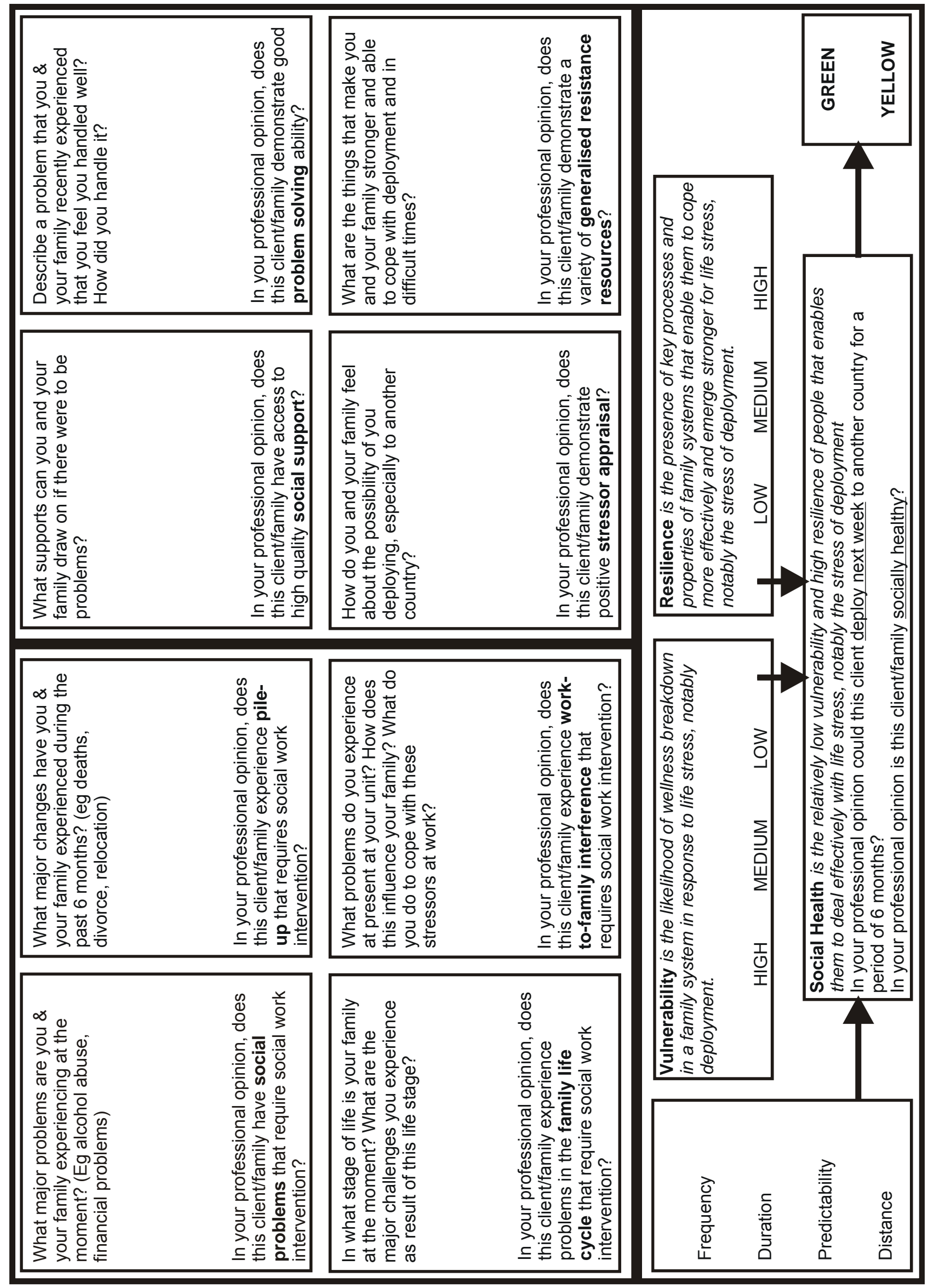


The RMAP was therefore designed: firstly, to guide the types of questions that social workers ask soldiers when assessing their resilience in order to obtain a comprehensive picture of both the vulnerability and resilience of the family; secondly, to assist social workers in recording the soldiers' responses and their own clinical observations in an orderly and systematic way, to facilitate later assessment and evaluation; and thirdly, to guide social workers in drawing professional and evidence-based conclusions from the data collected.

The eight blocks in the top half of the RMAP guide the types of questions asked and help social workers record clients' responses in systematic categories. These blocks correspond to the eight constructs of the Resilience Model. The top question in each block is asked of the client, while the bottom question is a summative question asked of the social worker. This grid allows haphazardly reported data to be recorded in a coherent way. The bottom half of the RMAP helps social workers integrate the data they have collected and draw professional conclusions about the vulnerability, resilience and social health of the client.

Approximately twenty military social workers were trained to use the RMAP. Informal feedback indicates that the RMAP assists social workers in translating a theoretical model into clinical practice, and that it helps them sort and group clinical data as they are collected. In a study on the validity of the MSHI we found that social workers who used the RMAP produced clinical conclusions that were more consonant with the MSHI than social workers who used no assessment tool. For example, we found that the correlations between the MSHI score and the social workers' clinical judgements were .21 for social workers not using the RMAP and .26 for those using the RMAP. This small but notable difference points to the value of a rigorous and systematic clinical assessment protocol.

\section{CASE STUDY}

The primary purpose of this paper has been to illustrate one organisation's attempt to translate the resilience and strengths perspectives into practice through the development of a trio of resilience-based assessment tools. These tools, however, are only as valuable as their utilisation. In this section, therefore, a case example is provided to illustrate the application of these tools. Use is made of a case example that formed part of the training of social workers in the use of these tools.

$\mathrm{X}$ is a 43-year-old soldier in the SA DOD, married with four children ranging from 6 to 16 years of age. X lives with his wife and children in a military house in Gauteng. He was referred to the social worker because his excessive use of alcohol was interfering with his ability to perform his job. This problem had, according to his supervisor, been going on for some time, but had recently come to a head because $\mathrm{X}$ wanted to deploy out of the country. His supervisor was concerned that his substance abuse could create disciplinary or performance problems in the deployment areas. The supervisor thus insisted that $\mathrm{X}$ see the social worker.

Following the protocol for deployment assessments, the social worker first requested $\mathrm{X}$ to complete the MSHI in a private and quiet venue. The question booklet is a 19-page document, printed in landscape view with four columns of text - English, Zulu, Afrikaans and Setswana. The social worker explained that X could complete the instrument in any language that he was comfortable in, or even compare the various language versions. The social worker also explained the purpose of the questionnaire and contracted for limited confidentiality.

The social worker oriented $X$ to the answer sheet, which is a separate single sheet of paper, with small circles for each item. Using the first question, "What is your home language (mother 
tongue)?" she explained and demonstrated how to fill in the answer sheet, by colouring in the appropriate circle. She then asked him to complete the second question, "Are you a male or a female?" and checked that he had done so correctly. Thereafter, she left X to complete the instrument independently.

After X had completed the MSHI, the social worker captured it into the computerised scoring programme and printed the results. The MSHI results indicated elevated vulnerability scores for social problems and work-to-family interference. In addition, there were low resilience scores for problem solving and generalised resistance resources, but a high resilience score for social support. The overall social health score, a combination of all seven subscales, indicated that $\mathrm{X}$ was not socially healthy and in need of professional assistance.

Based on the MSHI results, the social worker formulated a number of clinical hunches about X. He seemed to be experiencing a level of vulnerability that was overwhelming his resilience resources. This vulnerability seemed related to various social problems at home, which probably extended beyond his alcohol abuse. In addition, he was having difficulty regulating the relationship between his work and family. The presence of a high score for social support could indicate the presence of an asset in his family that could be mobilised to help him address his vulnerability. The low problem-solving score suggested that the problem-solving approach to social work could be helpful in equipping him with the life skills to face his own challenges more effectively.

With these hunches in mind, the social worker called $\mathrm{X}$ in for an interview using the RMAP. After contracting with $X$ and explaining the procedures to him, the social worker opened the A3-size RMAP and asked him to tell her what was happening at home. In the first half of the interview the social worker allowed $\mathrm{X}$ to take the lead, following up his statements with further questions. For example, $\mathrm{X}$ explained that he was worried about his oldest child, who had become involved with a "bad crowd" at school. This had resulted in his being suspended from the school for a week. The social worker wrote this information on the RMAP in the cell for social problems. The social worker enquired how old this child was, and learned that he was 16 years old. The social worker asked how the family was coping with having a teenager in the home, and it appeared that family life had become increasing conflicted over the past several years as the oldest child moved into adolescence. The social worker wrote this information on the RMAP in the cell for family life cycle. Through this assessment method, the social worker elicited a range of information and recorded it in the appropriate cells of the RMAP.

About half way through the interview the social worker paused to review the information she had obtained from X. It appeared that there were a number of gaps, particularly on the resilience side of the RMAP. She therefore began asking specific questions to fill in these gaps. She asked, for example, "What do you think are the things that make you and your family stronger and more able to cope with life?" to generate information about generalised resistance resources, as this cell was empty. In this way, she was able to ensure that she had comprehensively assessed both the vulnerability and resilience domains.

Based on these data, the social worker pulled together her assessment. She observed that X and his family were experiencing a number of life events that left the family vulnerable. These included X's substance abuse, which had been escalating over recent years, and the family's movement into the adolescent phase. The social worker found the $\mathrm{X}$ family to be conservative and battling to adjust to the new patterns that adolescence requires. It also emerged that various problems in the extended family, notably having to take care of X's sister who was ill with 
AIDS, was burdening this already over-extended family. Finally, there had been a change of management at X's work, which resulted in his being passed over for promotion. These work tensions were spilling into the family.

On the resilience side, the family had good social support from extended family, church and their neighbourhood. X was very positive about deploying, though the social worker suspected this was an attempt to avoid the family problems. The family's problem-solving skills, however, were poor - they tended to avoid identifying problems. In addition, the family's generalised resistance resources, while suitable to a younger family, were not appropriate for a family with an adolescent. As a result, their cherished traditions, such as eating dinner together or telling stories in the evenings, were under threat from a teenager who wanted to be more independent and grown-up.

Based on the mutually reinforcing evidence from the RMAP clinical assessment and the MSHI, the social worker found that the family's vulnerability overwhelmed their limited resilience. In such a context X's increased substance abuse was both a result and cause of the family's increased vulnerability. The social worker was concerned that X's deployment at this stage could cause further harm to the family system and recommended that $\mathrm{X}$ be kept at home for six months, during which time he and his family could attend family counselling.

Following the principles of the resilience and strengths perspectives, that mobilising family assets can enable families to deal with their own challenges, the social worker activated several people in the X family's social environment. She explored various approaches to problem solving with this social network to elicit contextually-appropriate problem solving methods. The strengthening of these resilience factors unleashed new energy in the family to begin recognising that their family was growing up and needed adjusting. This easing of family tension unintentionally resulted in a moderate decrease in X's abuse of alcohol. His wife and children, however, became more insistent that he address his drinking entirely, as it was having a negative effect on the whole family system. X agreed, somewhat reluctantly, to enter an alcohol treatment programme at the workplace.

\section{CONCLUSIONS}

The resilience perspective is highly congruent with the social work values of respect for human dignity and commitment to human rights. It is a view of humanity that recognises that, while people may face a range of adversities, discrimination, marginalisation and vulnerability, people often find ways to surmount these challenges, to cope and even to thrive. Within social work, resilience theory has been expressed most notably through the strengths perspective.

One of the limitations of the resilience and strengths perspectives, however, is that they do not easily translate into practice. There is often a tendency for these perspectives to emphasise viewpoint and values, but not adequately to address practice implications. This paper has endeavoured to present a package of applications of the resilience perspective with a specific client population - military families in South Africa.

This package includes a conceptual model of family resilience. This model seeks to describe (and even predict) what factors are likely to lead to family breakdown in the face of a military operation. The model includes both vulnerability and resilience factors. This model has strong support from the literature as well as from empirical studies in South Africa and elsewhere. With this model as a foundation, two tools have been developed to help social workers assess the resilience of military families. The first is a standardised, validated scale that measures the 
same constructs as the resilience model; the second is an assessment protocol that is used during clinical interviews of military families.

The process of developing this package illustrates the value of long-term rolling research within a particular field or agency. Initial clinical hunches were validated through exploratory, qualitative and resilience-based research. These data, combined with an extensive literature review, resulted in a theoretical framework with direct relevance for clinical practice. Based on these insights and local evidence, a rigorous, standardised assessment scale and a rigorous, clinical assessment protocol could be developed, tested and widely used. This entire process from exploratory research to evidence-based practice - took a little over ten years to complete.

This assessment package serves to illustrate how a commitment to resilience can be expressed in very tangible and practical ways in the delivery of social work services. This is not merely a commitment to the values of the strengths perspective, but an active and direct set of social work activities. The grounding of social work services in a model such as the Resilience Model and the use of the MSHI and RMAP create an integrated and holistic approach to social work in the military that is informed by the principles of the resilience and strengths perspectives.

\section{REFERENCES}

ANTONOVSKY, A. 1979. Health, stress, and coping. San Francisco, CA: Jossey-Bass.

ANTONOVSKY, A. 1988. Unraveling the mystery of health: how people manage stress and stay well. San Francisco, CA: Jossey-Bass.

BARNARD, C.P. 1994. Resiliency: a shift in our perception? American Journal of Family Therapy, 22(2):135-144.

BENDOR, S., DAVIDSON, K. \& SKOLNIK, L. 1997. Strengths-pathology dissonance in the social work curriculum. Journal of Teaching in Social Work, 15(1/2):3-16.

BLOOM, M., FISCHER, J. \& ORME, J.G. 1995. Evaluating practice: guidelines for the accountable professional. Boston, MA: Allyn \& Bacon.

DIRECTORATE SOCIAL WORK. 2001. Concurrent health assessment: social work manual. Unpublished manuscript, Directorate Social Work, South African National Defence Force, Pretoria, South Africa.

FRONE, M.R., YARDLEY, J.K. \& MARKEL, K.S. 1997. Developing and testing an integrative model of the work-family interface. Journal of Vocational Behavior, 50(2):145167.

GOLDSTEIN, H. 1997. Victors or victims? In: SALEEBEY, D. (ed) The strengths perspective in social work practice $\left(2^{\text {nd }} \mathrm{ed}\right)$. New York City, NY: Longman.

GOOGINS, B.K. 1991. Work/family conflicts: private lives - public responses. New York City, NY: Auburn House.

HAWLEY, D.R. \& DE HAAN, L. 1996. Toward a definition of family resilience: integrating life-span and family perspectives. Family Process, 35(3):283-298.

HEALY, K. 2005. Social work theories in context: creating frameworks for practice. New York City, NY: Palgrave MacMillan. 
KRETZMANN, J. \& McKNIGHT, J. 1993. Building communities from the inside out: a path toward finding and mobilizing a community's assets. Evanston, IL: Northwestern University.

McCUBBIN, H.I. \& McCUBBIN, M.A. 1992. Research utilization in social work practice of family treatment. In: GRASSO, A.J. \& EPSTEIN, I. (eds) Research utilization in the social sciences: innovations for practice and administration. New York City, NY: Haworth.

McCUBBIN, M.A. \& McCUBBIN, H.I. 1993. Families coping with illness: the resiliency model of family stress, adjustment, and adaptation. In: DANIELSON, C., HAMEL-BISSELL, B. \& WINSTEAD-FRY, P. (eds) Families, health, and illness. New York City, NY: Mosby.

McCUBBIN, M.A. \& McCUBBIN, H.I. 1996. Resiliency in families: a conceptual model of family adjustment and adaptation in response to stress and crises. In: McCUBBIN, H.I., THOMPSON, A.I. \& McCUBBIN, M.A. (eds) Family assessment: resiliency, coping and adaptation: inventories for research and practice. Madison, WI: University of Wisconsin.

NETEMEYER, R.G., BOLES, J.S. \& McMURRIAN, R. 1996. Development and validation of work-family conflict and family-work conflict scales. Journal of Applied Psychology, 81(4):400-410.

O'LEARY, V.E. 1998. Strength in the face of adversity: Individual and social thriving. Journal of Social Issues, 54(2):425-446.

PEARLIN, L.I. \& SCHOOLER, C. 1982. The structure of coping. In: McCUBBIN, H.I., CAUBLE, A.E. \& PATTERSON, J.M. (eds) Family stress, coping, and social support. Springfield, IL: Charles C Thomas.

RAK, C. \& PATTERSON, L. 1996. Promoting resilience in at-risk children. Journal of Counseling and Development, 74(4):368-373. [Online] Available: http://www.valdosta.peachnet.edu/ whuitt/psy702/files/resbuild.html. [Rev: 30/08/1998].

SALEEBEY, D. 1997. Introduction: power in the people. In: SALEEBEY, D. (ed) The strengths perspective in social work practice $\left(2^{\text {nd }}\right.$ ed). New York City, NY: Longman.

SALEEBEY, D. (ed) 2008. The strengths perspective in social work practice $\left(5^{\text {th }}\right.$ ed). Boston, MA: Allyn \& Bacon.

SCHWARTZ, R. 1997. Don’t look back. Networker, (March/April):40-47.

SEGAL, M.W. 1989. The nature of work and family linkages: a theoretical perspective. In: BOWEN, G.L. \& ORTHNER, D.K. (eds) The organization family: work and family linkages in the US military. New York City, NY: Praeger.

VAN BREDA, A.D. 1995. Coping with deployments. Unpublished manuscript, University of Cape Town, South Africa.

VAN BREDA, A.D. 1997a. The development of the Deployment Resilience Seminar. Cape Town, South Africa: School of Social Work, University of Cape Town. (Unpublished MA Thesis)

VAN BREDA, A.D. 1997b. Experience of routine husband absences. Social Work/Maatskaplike Werk, 33(2):154-164.

VAN BREDA, A.D. 1999. Developing resilience to routine separations: an occupational social work intervention. Families in Society, 80(6):597-605. 
VAN BREDA, A.D. 2001. Resilience theory: a literature review. Pretoria, South Africa: South African Military Health Service. [Online] Available: www.vanbreda. org/adrian/resilience.htm. [Rev: 09/03/2009].

VAN BREDA, A.D. 2002a. Social health assessment of soldiers' operational readiness. 34th International Congress on Military Medicine. Sun City, South Africa. [Online] Available: http://www.vanbreda.org/adrian/pubs.htm. [Rev: 12/08/2005].

VAN BREDA, A.D. 2002b. The utilisation of resilience theory in military social work. 34th International Congress on Military Medicine. Sun City, South Africa. [Online] Available: http://www.vanbreda.org/adrian/pubs.htm. [Rev: 12/08/2005].

VAN BREDA, A.D. 2004. Multicultural scale development in social work. Johannesburg, RSA: Rand Afrikaans University. (unpublished doctoral dissertation) [Online] Available: www.vanbreda.org/adrian.

VAN BREDA, A.D. 2008a. Designing questionnaires for use in multicultural contexts. Social Work/Maatskaplikewerk, 44(1):1-17.

VAN BREDA, A.D. 2008b. The Military Social Health Index: a partial multicultural validation. Military Medicine, 173(5):480-487.

WALSH, F. 1996. The concept of family resilience: crisis and challenge. Family Process, 35(3):261-281.

WEICK, A. \& SALEEBEY, D. 1995. Supporting family strengths: orienting policy and practice toward the 21st century. Families in Society, 76(3):141-149.

Prof Adrian D. van Breda,, Department of Social Work, University of Johannesburg, Johannesburg, South Africa. 